\title{
Regional Rodent-Borne Infectious Diseases in North America: What Wilderness Medicine Providers Need to Know
}

\author{
James H. Diaz, MD, MPH\&TM, DrPH, FASTMH \\ LSU School of Public Health, Louisiana State University Health Sciences Center in New Orleans, New Orleans, Louisiana
}

\begin{abstract}
Rodents can transmit infectious diseases directly to humans and other animals via bites and exposure to infectious salivary aerosols and excreta. Arthropods infected while blood-feeding on rodents can also transmit rodent-borne pathogens indirectly to humans and animals. Environmental events, such as wet winters, cooler summers, heavy rains, and flooding, have precipitated regional rodent-borne infectious disease outbreaks; these outbreaks are now increasing with climate change. The objectives of this review are to inform wilderness medicine providers about the environmental conditions that can precipitate rodent-borne infectious disease outbreaks; to describe the regional geographic distributions of rodent-borne infectious diseases in North America; and to recommend prophylactic treatments and effective prevention and control strategies for rodent-borne infectious diseases. To meet these objectives, Internet search engines were queried with keywords to identify scientific articles on outbreaks of the most common regional rodent-borne infectious diseases in North America. Wilderness medicine providers should maintain high levels of suspicion for regional rodent-borne diseases in patients who develop febrile illnesses after exposure to contaminated freshwater after heavy rains or floods and after swimming, rafting, or paddling in endemic areas. Public health education strategies should encourage limiting human contact with rodents; avoiding contact with or safely disposing of rodent excreta; avoiding contact with contaminated floodwaters, especially contact with open wounds; securely containing outdoor food stores; and modifying wilderness cabins and campsites to deter rodent colonization.
\end{abstract}

Keywords: climate change, Hantaviruses, leptospirosis, plague, Yersinia pestis

\section{Introduction}

Rodents can transmit several bacterial and viral infectious diseases directly to humans and other animals via bites and exposure to infectious salivary aerosols and excreta (Table 1). Arthropod vectors, such as mites, ticks, and fleas, can also indirectly transmit pathogens from infected rodent hosts to humans and animals by their bites (Table 1). Rodents are both reservoirs and vectors of

Corresponding author: James H. Diaz, MD, DrPH, LSU School of Public Health, Louisiana State University Health Sciences Center in New Orleans, 2020 Gravier Street, Third Floor, New Orleans, Louisiana 70112; e-mail: jdiaz@1suhsc.edu.

Submitted for publication November 2020.

Accepted for publication March 2021. several pathogens that can cause infection without clinical disease. Environmental events, such wet winters followed by cooler summers, heavy rains, and flooding, have precipitated regional rodent-borne infectious disease outbreaks by forcing rodents from their burrows near food and freshwater sources into developed environments and closer to humans. ${ }^{1-9}$

The objectives of this review are to inform wilderness medicine providers of the environmental conditions that can precipitate outbreaks of rodent-borne infectious diseases; to describe the geographic distributions of rodentborne infectious diseases in North America; to describe the epidemiologic features and presenting clinical manifestations and outcomes of the most common rodent-borne infectious diseases; and to recommend prophylactic therapies and effective prevention and control strategies for rodent-borne infectious disease outbreaks. 
Table 1. Infectious diseases directly transmitted by rodents and indirectly transmitted by arthropod vectors feeding on rodents

\begin{tabular}{|c|c|c|}
\hline Direct transmission $^{a}$ & Indirect transmission $^{b}$ & Arthropod vectors \\
\hline Hantavirus cardiopulmonary syndrome & Anaplasmosis & Dermacentor ticks \\
\hline Hantavirus hemorrhagic fever with renal syndrome & Babesiosis & Ixodes ticks \\
\hline Lassa fever & Colorado tick fever & Dermacentor ticks \\
\hline Leptospirosis & Cutaneous (sylvatic) leishmaniasis & $\begin{array}{l}\text { Lutzomyia sandflies (Americas) } \\
\text { Phlebotomus sandflies (Old World) }\end{array}$ \\
\hline Lymphocytic choriomeningitis & Epidemic typhus & Pediculus corporis (body louse) \\
\hline Omsk hemorrhagic fever & La Crosse encephalitis & Aedes mosquitoes \\
\hline Plague & Lyme disease & Ixodes ticks \\
\hline Rat-bite fever & Murine typhus & Fleas \\
\hline Salmonellosis & Omsk hemorrhagic fever & Dermacentor ticks \\
\hline South American Andes virus ${ }^{c}$ & Powassan virus & Ixodes ticks \\
\hline South American Arenaviruses & Scrub typhus & Leptotrombidium mites \\
\hline
\end{tabular}

Argentine hemorrhagic fever

Bolivian hemorrhagic fever

Sabiá-associated hemorrhagic fever

Venezuelan hemorrhagic fever

Tularemia
Relapsing fever
Rocky Mountain spotted fever
Salmonellosis
Tularemia
West Nile virus

Ornithodorus ticks
Dermacentor ticks
Flies
Fleas, flies, midges, and ticks
Culex mosquitoes

Source: CDC Fact sheet about Andes virus. Available at: https://www.cdc.gov/hantavirus/resources/andes-virus.html\#::text=Andes\%20virus $\% 20$ is $\% 20$ a\% 20type.

Partial source: Available at http://www.cdc.gov/rodents/diseases

${ }^{\mathrm{a}}$ Direct transmission: Diseases transmitted directly by rodent bites; by ingestion of rodent excreta-contaminated food or water; or by inhalation of or transmucosal exposures to infectious aerosols of rodent saliva or excreta.

${ }^{b}$ Indirect transmission: Diseases transmitted indirectly by bites from infected arthropod vectors feeding on infected rodent hosts or their excreta, or by bites from infected arthropod vectors exposed to infectious rodent aerosols or excreta.

${ }^{c}$ Andes virus is a South American Hantavirus found in rodents primarily in Argentina and Chile that can cause an initial influenza-like illness and progress to a cardiopulmonary syndrome $4 \mathrm{~d}$ to $6 \mathrm{wk}$ after exposure to infected rodents or their aerosols or excreta. Andes virus is the only Hantavirus known to be transmitted from person to person by direct contact with a symptomatic person for a prolonged period $(>1 \mathrm{~h})$ or by contact with infectious bodily fluids. Nosocomial transmission has occurred.

\section{Methods}

To meet the study's objectives, Internet search engines, including Google, Google Scholar, PubMed, Medline, and Ovid, were queried to examine peer-reviewed scientific articles on the most common regional rodent-borne infectious disease outbreaks in North America. The keywords included climate change, Hantaviruses, leptospirosis (LS), plague, and Yersinia pestis. The study period was defined as 1970 to 2020 . The articles reviewed included microbiological articles, meteorological/climate change studies, disease surveillance studies, review articles, case reports and series, and disease outbreak investigations (Table 2). Articles reviewed but excluded as references included

Table 2. Scientific articles reviewed, referenced, and stratified by subtypes

\begin{tabular}{lllllll}
\hline \multirow{2}{*}{ Methods } & \multicolumn{6}{c}{ Stratification by subtype } \\
\cline { 2 - 7 } & $\begin{array}{l}\text { Microbiological } \\
\text { articles }\end{array}$ & $\begin{array}{l}\text { Disease } \\
\text { surveillance } \\
\text { studies }\end{array}$ & $\begin{array}{l}\text { Outbreak } \\
\text { investigations }\end{array}$ & $\begin{array}{l}\text { Meteorologic/ Case } \\
\text { Climate } \\
\text { change } \\
\text { articles }\end{array}$ & $\begin{array}{l}\text { Review } \\
\text { reports } \\
\text { series }\end{array}$ & $\begin{array}{c}\text { Totals } \\
\text { articles }\end{array}$ \\
\hline $\begin{array}{c}\text { Reviewed and } \\
\text { stratified }\end{array}$ & 5 & 10 & 4 & 14 & 15 & 10 \\
Referenced
\end{tabular}




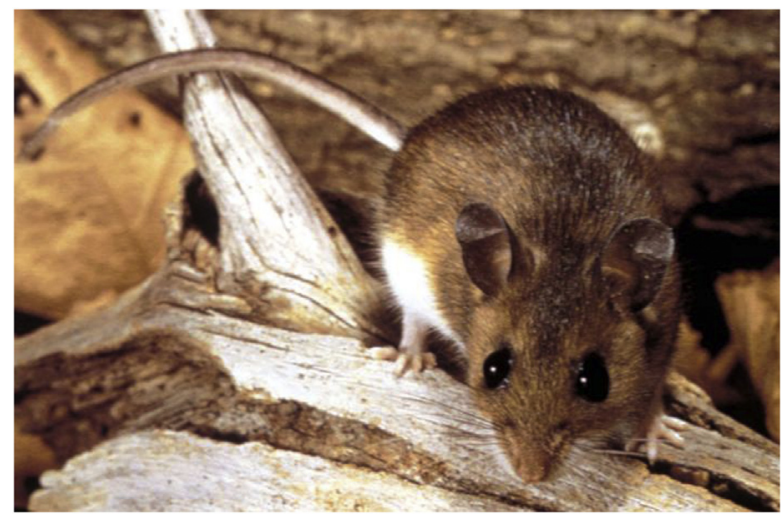

Figure 1. A North American deer mouse, Peromyscus maniculatus, which serves as the rodent reservoir and transmitter of the Sin Nombre Hantavirus in Western Canada, California, and the Southwest United States. Source: United States Centers for Disease Control and Prevention. Public domain. Available at: https://phil.cdc.gov/Details.aspx? pid $=8358$. Photo credit: James Gathany, CDC.

letters to the editor, dispatches, opinion-editorial articles, clinical-pathological case conferences, and abstracts of posters and presentations at conferences and scientific meetings. This methodology met all recommended criteria for narrative reviews, including use of several keywords, 2 or more Internet search engines, a defined study period, and article inclusion and exclusion criteria. ${ }^{10}$ Institutional review board approval was not required for this review of peer-reviewed scientific publications.

\section{Results}

\section{THE IMPACT OF CLIMATIC PATTERNS ON REGIONAL RODENT-BORNE INFECTIOUS DISEASES}

Unanticipated regional outbreaks of Hantavirus cardiopulmonary syndrome (HCPS) have occurred after periods of relative drought followed by heavy rainfall in the United States. ${ }^{1,3,4}$ During the spring of 1993, the first New World Hantavirus to be identified in the United States, later named Sin Nombre virus, caused a cluster outbreak of severe pneumonia with cardiopulmonary failure in 24 young, healthy patients, 18 of whom died. ${ }^{11,12}$ All 18 cases were clustered in the Four Corners region of the southwestern United States where the borders of 4 states (Arizona, Colorado, New Mexico, and Utah) meet. ${ }^{11,12}$ Subsequent investigations by mammologists from the United States Centers for Disease Control and Prevention (CDC) confirmed that the increased precipitation and moisture from an $\mathrm{El} \mathrm{Niño}$ winter spawned abundant vegetation with a seed crop that provided shelter and food for the regional rodent population of deer mice (Peromyscus maniculatus) (Figure 1). ${ }^{13}$ Subsequent explosive growth in the deer mouse population increased the likelihood of human exposure to the infectious secretions of rodent vectors, setting the stage for the first Hantavirus outbreak in the United States. ${ }^{2,13}$

During the summer of 2012, after a rainy winter and spring, 10 cases of Sin Nombre Hantavirus infections

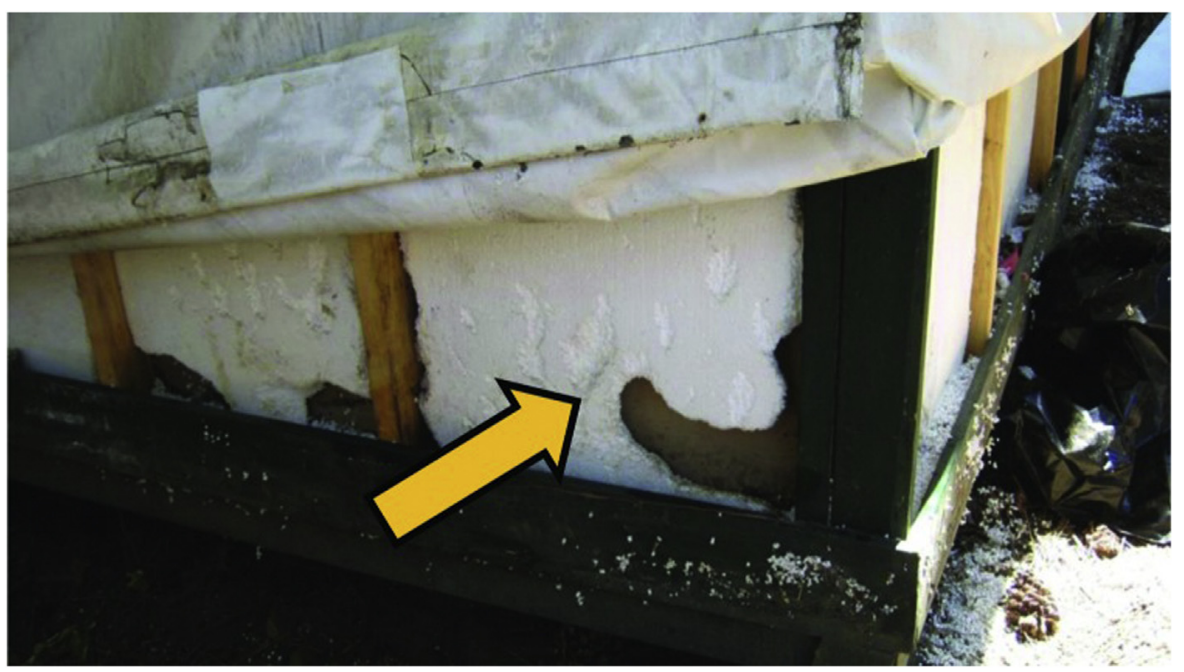

Figure 2. Damage (yellow arrow) from deer mice tunneling in the foam insulation of a signature tent cabin in Yosemite National Park, California, the site of a Sin Nombre Hantavirus outbreak during the summer of 2012. Source: United States Centers for Disease Control and Prevention. Public domain. Reference: Nuñez et al. ${ }^{15}$ Available at: https://www.ncbi.nlm.nih.gov/core/lw/2.0/html/tileshop_pmc/tileshop_pmc_inline.html?title=Click $\% 20$ on\%20image $\% 20$ to\%20zoom\&p=PMC3\&id=3944872_13-1581-F4.jpg. 


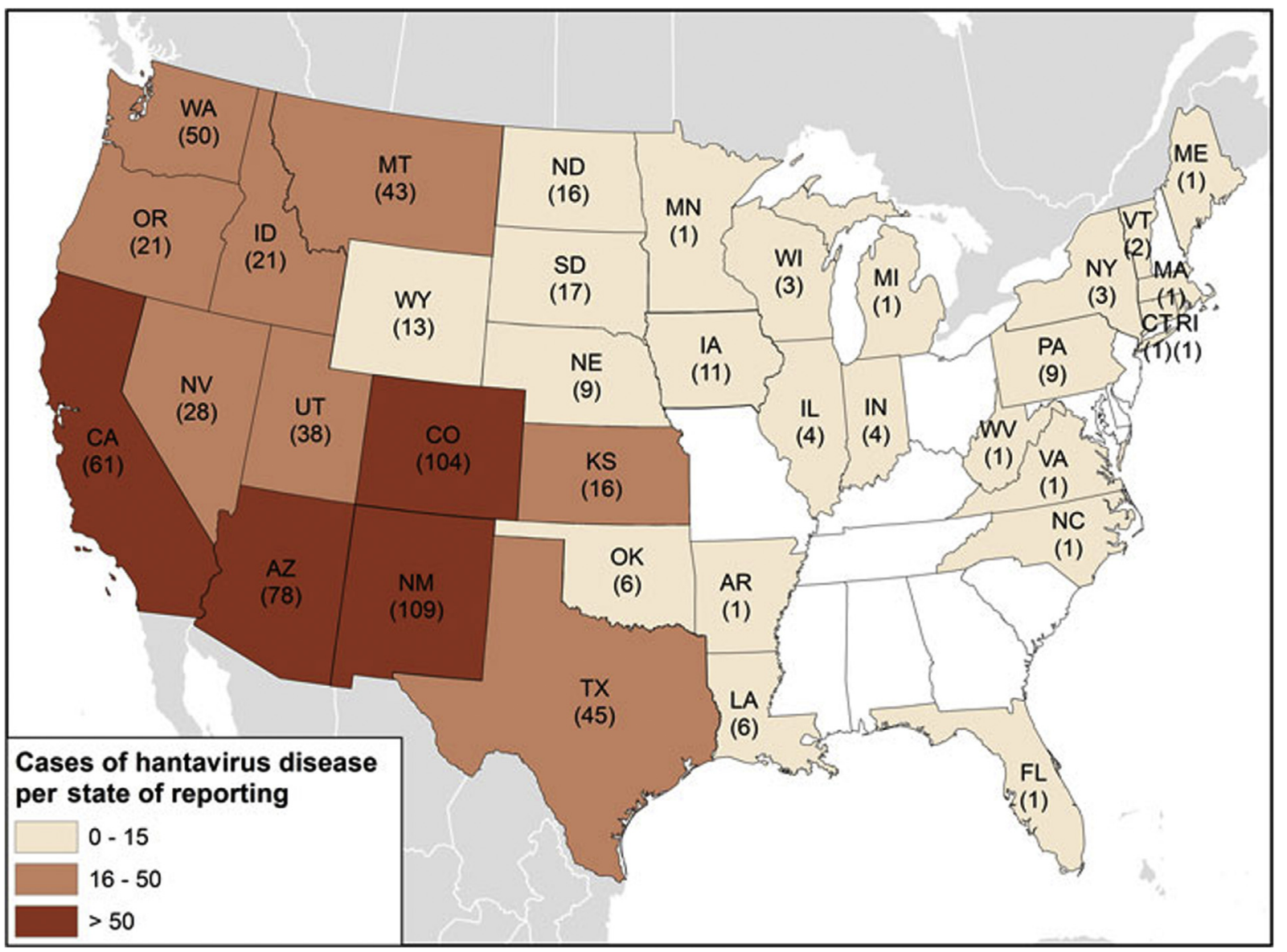

Figure 3. Geographic distribution of total cases of Hantavirus diseases $(n=728)$ since 1993 by states of reporting as of 2017, continental United States. Source: United States Centers for Disease Control and Prevention. Public domain. Available at: https://www.cdc.gov/hantavirus/surveillance/ reporting-state.html.

occurred in overnight visitors to California's Yosemite National Park, 9 of whom stayed in panel-walled, canvascovered (or signature-level) tent cabins (Figure 2). ${ }^{14,15}$ Eight patients developed HCPS, 5 required mechanical ventilation for respiratory failure in intensive care, and 3 patients died. ${ }^{14,15}$ Staying overnight in a signature tent cabin in the park was significantly associated $(P<0.001)$ with the risk of becoming infected with Hantavirus. ${ }^{15}$ Rodent tunnels and nesting sites were identified in the foam insulation of the tent cabins (Figure 2). ${ }^{15} \mathrm{CDC}$ mammologists later detected antibodies to Sin Nombre Hantavirus in 10 of 73 (14\%) locally captured deer mice. ${ }^{15}$ The case fatality rate for HCPS caused by the $\operatorname{Sin}$ Nombre virus in the Yosemite outbreak was 33\%, which was consistent with the current North American case fatality rate for HCPS of 30 to $35 \% .^{16}$

The Sin Nombre virus is transmitted to humans by infective secretions from deer mice and remains the most common cause of HCPS in the United States and Canada
(Figure 1). Most cases are regionally confined to California and the Four Corners region in the United States and to the western provinces in Canada, especially Alberta (Figures 3 and 4). ${ }^{12,17}$ Heavy winter and spring precipitation followed by cooler summers have preceded Sin Nombre Hantavirus outbreaks in the infected deermouse-endemic regions of the United States and Canada. $^{12,17}$

LS is a rodent zoonosis that, like Hantavirus, causes infection without clinical disease in rodents. Transmission to humans occurs through exposure to floodwater and sediment contaminated with the urine of infected rodents. Regional LS outbreaks have occurred after flooding in Hawaii and Europe, typhoons in Asia, and tropical storms and hurricanes in the southeastern United States. ${ }^{2,5-8}$

In a 2013 descriptive epidemiologic analysis of hospitalized patients with LS after a typhoon in the Philippines, investigators reported 259 laboratory-confirmed cases out 


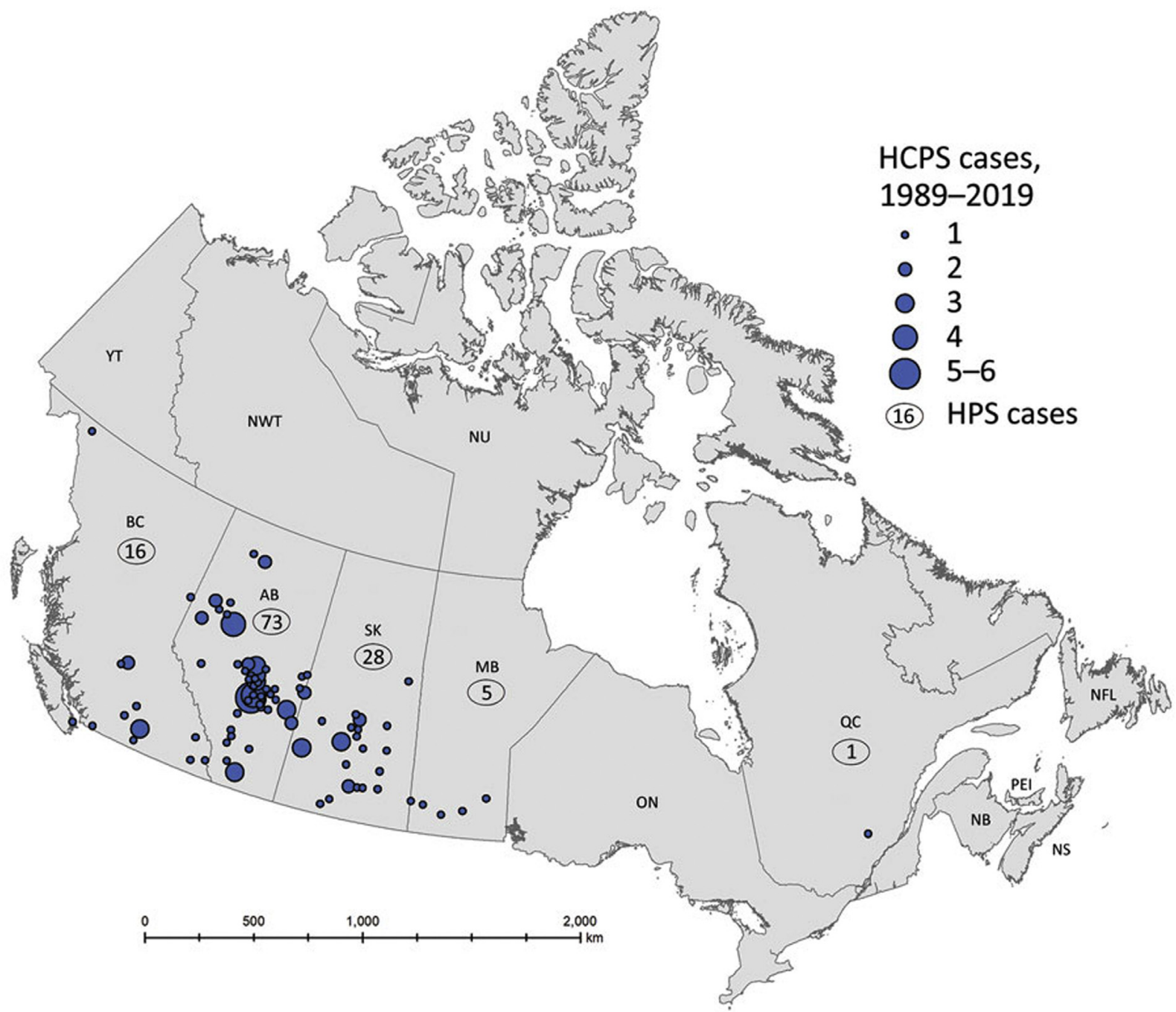

Figure 4. Geographic distribution of total cases of Hantavirus cardiopulmonary syndrome ( $\mathrm{n}=143)$ caused by the Sin Nombre Hantavirus by reporting Canadian provinces, 1989-2019. Source: United States Centers for Disease Control and Prevention. Public domain. Reference: Warner et al. ${ }^{17}$ Available at: https://wwwnc.cdc.gov/eid/article/26/12/20-2808-f1.

of 670 possible cases. ${ }^{7}$ Of the confirmed cases, the mean patient age was $39 \mathrm{y}$, and most were males $(82 \%)$ who had waded in floodwaters $(98 \%)^{7}$ Fever was the most common presenting symptom $(99 \%)$, followed by myalgia $(78 \%)$, malaise $(75 \%)$, conjunctival suffusion $(59 \%)$, oliguria $(57 \%)$, diarrhea $(39 \%)$, and jaundice $(38 \%){ }^{7}$ Complications included renal failure, pulmonary hemorrhage, meningitis, and myocarditis. ${ }^{7}$ The mortality rate was $5 \%$, primarily owing to pulmonary hemorrhage. ${ }^{7}$ The investigators recommended that clinicians maintain a high index of suspicion for LS during monsoon seasons when heavy rains and typhoons could lead to flooding. 7

Although plague is often considered a rodent-borne disease, rodents are only the animal reservoirs of the plague bacterium and not the vectors of Yersinia pestis, which is transmitted via the bite of plague-infected rodent fleas. In a 1999 descriptive epidemiologic analysis of human plague cases in New Mexico, investigators reported that cases occurred more frequently after periods of above-average winter and spring precipitation. ${ }^{9}$ Like cases of Sin Nombre Hantavirus, most cases of plague occur in the Southwest, mostly in California and the Four Corners region.

In summary, rodent-borne infectious disease outbreaks of HCPS, LS, and plague spawned by favorable weather patterns have been increasing in endemic regions across North America, especially in the Four Corners area and subtropical and tropical regions in the United States and in western Canada. 
Table 3. North American Hantaviruses capable of causing the Hantavirus cardiopulmonary syndrome

\begin{tabular}{|c|c|c|c|}
\hline North American Hantavirus species & $\begin{array}{l}\text { Rodent reservoirs } \\
\text { (common names) }\end{array}$ & $\begin{array}{l}\text { Rodent reservoirs } \\
\text { (Latin names) }\end{array}$ & $\begin{array}{l}\text { Geographic } \\
\text { distributions (North } \\
\text { America) }\end{array}$ \\
\hline Bayou & Marsh rice rat & Oryzomys palustris & Louisiana, Texas \\
\hline Black Creek Canal & Cotton rat & Sigmodon hispidus spadicipygus & $\begin{array}{l}\text { Southeast United } \\
\text { States, Florida }\end{array}$ \\
\hline Bloodland Lake $^{a}$ & Prairie vole & Microtus ochrogaster & Missouri \\
\hline El Moro Canyon & Western harvest mouse & Reithrodontomys megalotis & $\begin{array}{c}\text { Canada, western } \\
\text { United States }\end{array}$ \\
\hline Isla vista ${ }^{a}$ & California vole & Microtus californicus & $\begin{array}{l}\text { Pacific Northwest } \\
\text { United States, } \\
\text { California }\end{array}$ \\
\hline Limestone Canyon $^{a}$ & Brush mouse & Peromyscus boylii & $\begin{array}{l}\text { Southwest United } \\
\text { States }\end{array}$ \\
\hline Monongahela & Deer mouse & Peromyscus maniculatus & $\begin{array}{l}\text { Pennsylvania, West } \\
\text { Virginia }\end{array}$ \\
\hline Muleshoe & Cotton rat & Sigmodon hispidus texianus & $\begin{array}{l}\text { Southeast United } \\
\text { States, Florida, } \\
\text { Texas }\end{array}$ \\
\hline New York & White-footed mouse & Peromyscus leucopus & $\begin{array}{l}\text { Canada, New England } \\
\text { States }\end{array}$ \\
\hline Prospect Hill $^{a}$ & Meadow vole & Microtus pennsylvanicus & $\begin{array}{l}\text { Canada, throughout } \\
\text { United States }\end{array}$ \\
\hline Sin Nombre & Deer mouse & Peromyscus maniculatus & $\begin{array}{l}\text { Canada, western } \\
\text { United States }\end{array}$ \\
\hline
\end{tabular}

${ }^{a}$ Human diseases caused by these North American Hantaviruses have not been reported to date. All other Hantaviruses listed have caused the Hantavirus cardiopulmonary syndrome in North America.

\section{HANTAVIRUS IN THE UNITED STATES AND CANADA}

The Hantaviruses are a single genus of enveloped, singlestranded RNA bunyaviruses that cause infection without disease in rodents and insectivores, such as shrews and voles. There are about 40 species of Hantaviruses, which are divided into 2 strains based on their geographic distribution and clinical manifestations. The New World Hantaviruses target the lungs and cause pulmonary edema and effusions with respiratory failure and cardiovascular depression, whereas the Old World Hantaviruses target the vascular system and the kidneys, causing hemorrhagic shock and renal failure (Table 3).

Since the Four Corners outbreak in 1993, the CDC has maintained a registry of all Hantavirus cases in the United States. From 1993 to 2009, there were 510 confirmed cases of HCPS, with case counts ranging from 11 to 48 per year and case fatality rates averaging $35 \% .{ }^{18}$ During this period, cases were reported from 30 states, but most cases occurred in the southwestern United States. ${ }^{18}$ From 1993 to 2013, there were 624 confirmed cases of HCPS, with most cases caused by Sin Nombre virus in states west of the Mississippi River. ${ }^{19}$ In addition, 12 Hantavirus cases were reported from the eastern United States and were caused by other New World Hantaviruses, including Bayou, Black Creek Canal, New York, and Monongahela Hantaviruses (Figure 3). ${ }^{19}$ From 1993 to 2015, a descriptive analysis of the exposure characteristics of 662 confirmed cases of HCPS identified Native Americans in the southwestern United States as accounting for $18 \%$ of cases, with higher case-fatality rates (46\%) than whites $(33 \%) .{ }^{20}$ Seventeen percent of casepatients reported rodent exposure, with $71 \%$ of rodent exposures occurring in homes, $32 \%$ at work, and $24 \%$ in recreational settings such as parks and riversides. ${ }^{20}$

From 1993 to January 1, 2020, the Public Health Agency of Canada reported 143 confirmed cases of HCPS for an average of 4 to 5 cases per year (range 0-13 cases) with a seasonal peak in May and June, driven by the combination of outdoor human contact with an expanded deer mouse (Peromyscus maniculatus) population during favorable seasons (Figure 1). ${ }^{17}$ The mean age of case patients was $40 \mathrm{y}$ with a male preponderance (99 of 143 cases). ${ }^{17}$ All cases were caused by Sin Nombre virus, and all cases except 1 occurred in the 4 westernmost Canadian provinces of Alberta, British Columbia, Manitoba, and Saskatchewan, with Alberta having more cases than any other province (Figure 4). ${ }^{17}$ 


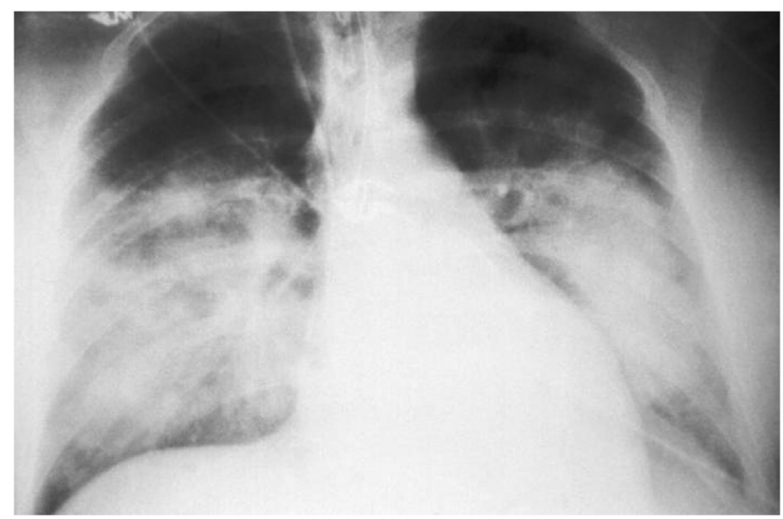

Figure 5. This anterior-posterior portable chest x-ray reveals the midstaged bilateral pulmonary effusions in a patient with the Hantavirus cardiopulmonary syndrome. Source: United States Centers for Disease Control and Prevention. Public domain. Available at: https://phil.cdc. gov/Details.aspx?pid=6076. Photo credit: D. Loren Ketai, MD.
In summary, active surveillance systems have demonstrated that HCPS cases caused by New World Hantaviruses, primarily the Sin Nombre virus, are being reported more frequently today in both the western United States and western Canada, especially in hyperendemic regions, such as the US Four Corners region and Alberta (Figures 3 and 4). In addition, other New World Hantaviruses with different rodent reservoirs are causing a few cases of HCPS in the eastern United States (Table 3).

Although bites by infected, asymptomatic rodents can transmit Hantaviruses, humans are most commonly infected by inhalation of aerosolized virions from rodent excreta in enclosed spaces, often during sweeping and clean-up of rodent nesting sites. ${ }^{12,13}$ Infected mice copiously shed Hantavirus in urine, feces, and saliva, with virions remaining viable and infective for up to $15 \mathrm{~d} .{ }^{15,16}$

\section{Plague Ecology in the United States}
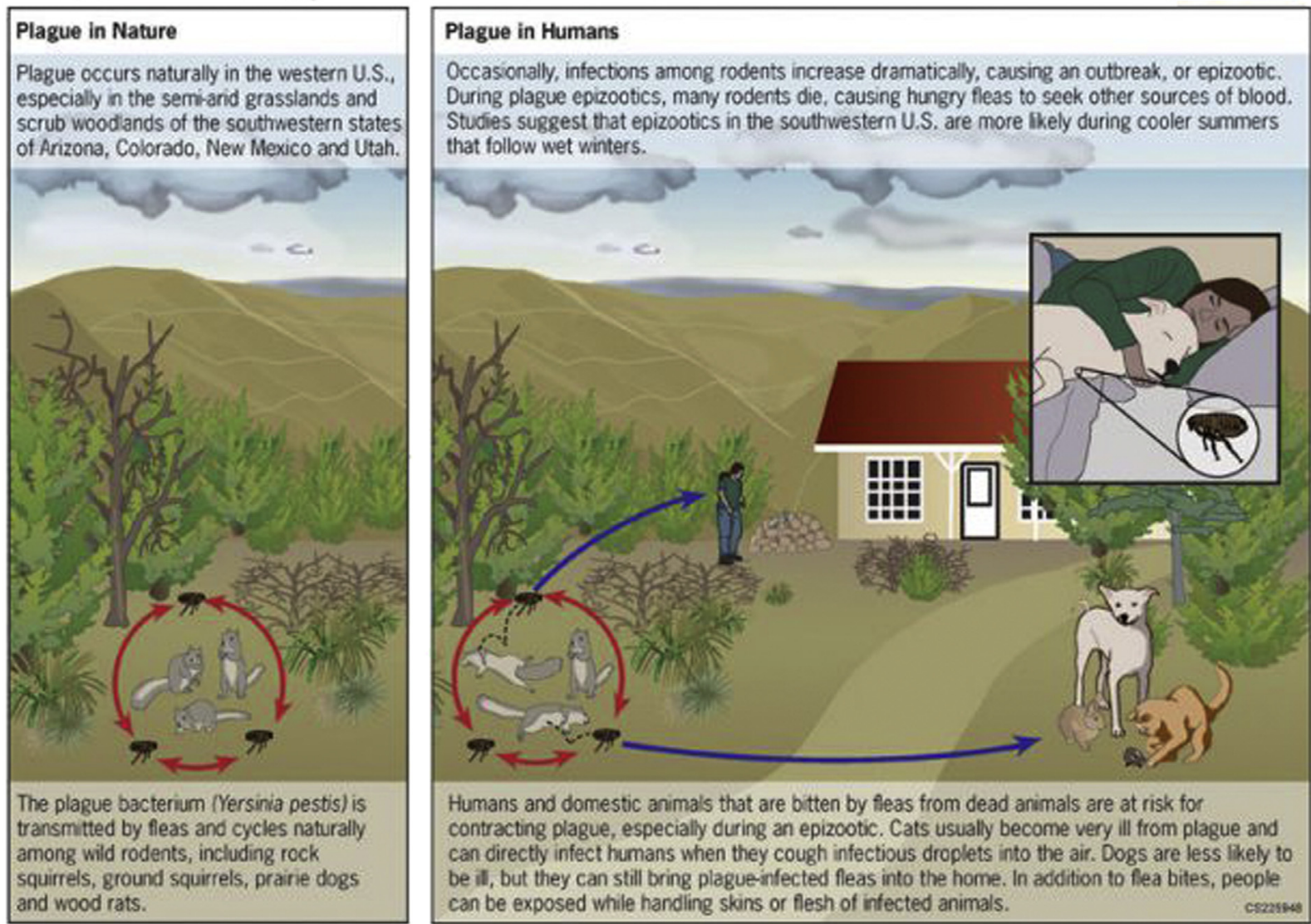

Figure 6. The sylvatic enzootic and epizootic transmission cycles of plague in the western United States. Source: United States Centers for Disease Control and Prevention. Public domain. Available at: https://www.cdc.gov/plague/resources/PlagueEcologyUS.pdf. 


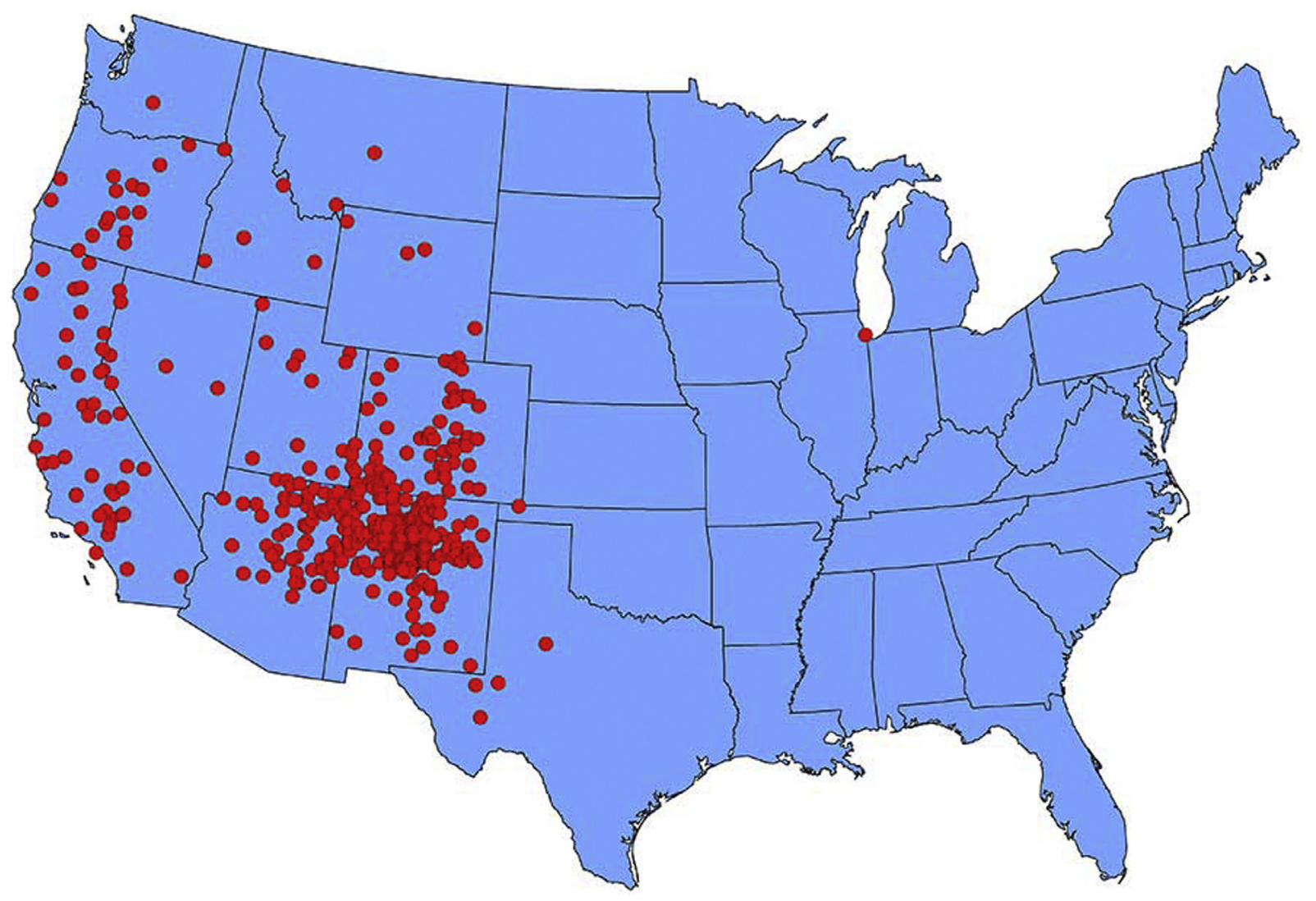

Figure 7. Geographic distribution of cases of human plague by state of reporting, continental United States, 1970-2018. Source: United States Centers for Disease Control and Prevention. Public domain. Available at: https://www.cdc.gov/plague/maps/index.html.

After an incubation period of 9 to $33 \mathrm{~d}$ (median 14-17 d), a prodromal febrile phase occurs with chills, headache, myalgias, and vomiting, followed within 3 to $7 \mathrm{~d}$ by a cardiopulmonary phase with cough, dyspnea, pulmonary edema and effusions, and respiratory failure requiring mechanical ventilation (Figure 5).

The serologic diagnosis of HCPS may be made, especially in endemic areas, based on the results of a commercial enzyme-linked immunosorbent assay test for antihantavirus immunoglobulins (IgM and/or IgG). Because many serologic tests for the diagnosis of HCPS may cross-react with other New World Hantaviruses endemic in the United States, specific Hantavirus identification by polymerase chain reaction with RNA sequencing of acute specimens collected early in the illness is recommended. Because there is no vaccine or specific antiviral therapy (including ribavirin) for HCPS, only early diagnosis and intensive supportive care, potentially including extracorporeal membrane oxygenation and nitric oxide administration, will reduce the high case fatality rates of HCPS. Wilderness medicine providers should consider a diagnosis of HCPS in persons with febrile illnesses that progress rapidly to respiratory insufficiency after rodent exposure in enclosed spaces, especially in endemic regions experiencing favorable seasonal weather patterns.

\section{LEPTOSPIROSIS}

LS is now the most commonly reported rodent-borne infectious disease and the most common zoonotic disease worldwide. ${ }^{5,21-24}$ LS has been classified as a reemerging infectious disease by both the CDC and the World Health Organization. $^{22,23}$ Fortunately, only about $10 \%$ of patients experience severe clinical disease and complications from LS and require hospitalization. ${ }^{21,22}$ Between 100 and 200 cases of LS are reported every year in the United States, with most cases reported from Hawaii, where the incidence is increasing during the rainy seasons and on Kauai, the wettest island. ${ }^{21,22}$ In a 2011 analysis of LS cases reported to the Hawaii State Department of Health during the period of 1998 to 2008 , investigators identified 345 case reports related to in-state exposures, 198 (57\%) of which were laboratory confirmed. ${ }^{22}$ 
Table 4. Rodent reservoirs of plague in the Western United States ${ }^{27,28}$

\begin{tabular}{lll}
\hline Rodent reservoirs (common names) & Rodent reservoirs (Latin names) & State distributions (Continental United States) \\
\hline Lodgepole chipmunk & Tamias speciosus & California \\
California ground squirrel & Otospermophilus beecheyi & California \\
Golden-mantled ground squirrel & Callospermophilus lateralis & California \\
Wood rats & Neotoma $\mathrm{spp}$ & Arizona, Colorado, New Mexico, Utah \\
Rock squirrel & Spermophilus variegatus & Arizona, Colorado, New Mexico, Utah \\
White-tailed antelope squirrel & Ammospermophilus leucurus & Arizona, Colorado, New Mexico, Utah \\
Prairie dogs & Cynomys spp & Arizona, Colorado, New Mexico, Utah \\
\hline
\end{tabular}

In a 2014 analysis of hospital discharge records for 1998 to 2009, investigators reported that the average annual rate of LS-associated hospitalizations was 0.6 hospitalizations per $1,000,000$ population. ${ }^{25}$ Hospitalization rates were highest for males $>20 \mathrm{y}$ of age. ${ }^{25}$

Leptospires are motile spirochetes of the family Leptospiraceae, with nearly 300 serotypes divided into human pathogenic strains and saprophytic strains. ${ }^{22,23}$ The larger group of pathogenic leptospires comprises the Leptospira interrogans sensu lato complex, with over 200 serotypes. ${ }^{22,23}$ Although the kidneys of many wild and domestic mammals serve as reservoir hosts for leptospires, rodents, primarily rats and mice, are the most common reservoirs worldwide. ${ }^{22,23}$ Like the Hantaviruses, leptospires cause infection without disease in their rodent hosts. Infected rodents excrete leptospires in their urine; these proliferate in freshwater, mud, moist soil, and wet vegetation and remain viable and infectious for months. ${ }^{22,23}$ As heavy rains and flooding saturate soil and surface vegetation, leptospires percolate into ground and surface waters, contaminating inland freshwater systems, including lakes and rivers. ${ }^{22,23}$

Human LS infections are transmitted most commonly by direct or indirect contact of mucous membranes, including conjunctivae, or abraded or broken skin with the urine of infected rodents or contaminated surface waters or sediments. ${ }^{22,24}$ Less common modes of transmission include rodent bites, ingestion of rodent urine-contaminated water or food, inhalation of infectious aerosols of rodent excreta, congenital transmission, and transmission after breastfeeding, blood transfusions, and organ transplants. ${ }^{22,23}$ Person-to-person transmission is possible, but rarely described ${ }^{22,23}$

After an incubation period of $7 \mathrm{~d}$ (range 2-29 d), LS displays a wide spectrum of clinical manifestations, ranging from a mildly symptomatic subclinical infection in most cases $(80 \%)$, to a syndrome of abrupt fever, headache, myalgia, nausea, vomiting, and an occasional maculopapular rash that resolves in a week, to a biphasic illness that starts with fever, myalgia, and conjunctival suffusion in the first week and progression to icteric LS or
Weil's disease in 5 to $10 \%$ of cases. ${ }^{5,22,23}$ Weil's disease is characterized by jaundice, thrombocytopenia, acute renal failure, respiratory distress, and cardiac arrhythmias. ${ }^{22,23}$ Weil's disease occurred in 2 out of 74 patients in a triathlon-associated outbreak of LS and had a 1 to $5 \%$ case fatality rate that increased with increasing age. ${ }^{24,26}$

The differential diagnosis of LS is broad and includes most febrile infectious diseases, including HCPS and Hantavirus hemorrhagic fever with renal failure syndrome, and relies on a careful exposure history and clinical suspicion supported by serologic testing. The microscopic agglutination test is the most reliable test for LS, but it is time-consuming and only offered by reference laboratories. ${ }^{22,23}$ Because IgM antibodies cannot be detected until 5 to $7 \mathrm{~d}$ into the illness, acute serologic tests may be negative initially and positive later in the illness and during convalescence. Cultures of leptospires from blood or urine are time-consuming and of limited value in clinical management. Antibiotic therapy with oral doxycycline, ampicillin, amoxicillin, erythromycin, or azithromycin is recommended for mild cases, with intravenous therapy with ceftriaxone or penicillin $G$ recommended for severe cases. ${ }^{22,23}$

Chemoprophylaxis with doxycycline, $200 \mathrm{mg} \cdot \mathrm{wk}^{-1}$, has an efficacy rate of $95 \%$ and should be considered for soldiers on tropical training maneuvers and for triathletes participating in competitive swimming or whitewater paddling events in tropical, LS-endemic areas. ${ }^{26}$ Given the challenges of early diagnosis of LS, empiric treatment with effective oral antibiotics should also be considered in symptomatic patients with highrisk exposures, especially in hyperendemic areas such as Hawaii.

Although vaccines are under development for LS, none are universally available. The best preventive strategies include drinking boiled or bottled water and minimizing exposure to rodent urine-contaminated environments by wearing waterproof boots and clothing. All cuts and abrasions should be covered with waterproof dressings. Triathletes participating in distance swimming events, kayakers, and whitewater rafters should wear 
goggles to prevent transconjunctival transmission and avoid submersion in and ingestion of freshwater. ${ }^{23,26}$

Wilderness medicine providers should maintain high levels of suspicion for LS outbreaks after flooding events and freshwater exposure and immersion during outdoor recreational events. Public health officers should immediately promote heightened awareness of LS outbreaks among all flood-affected populations.

\section{PLAGUE}

Plague is caused by the aerobic, gram-negative coccobacillus Yersinia pestis and is maintained in endemic regions in enzootic, sylvatic cycles among rodents and their fleas (Figure 6). In North America, plague is endemic in California and other western states, especially Arizona, Colorado, New Mexico, and Utah (Figure 7).

As observed by investigators in New Mexico, human plague cases are more frequent during cooler summers that follow above-average precipitation in winter and spring, conditions that result in an abundant food source for an expanded rodent population. ${ }^{9}$ As rodent densities increase in new habitats, there is a greater likelihood of flea-transmitted plague in wild animals, such as cougars and rabbits, and in domestic pets, such as cats and dogs (Figure 6). ${ }^{9,27-29}$

Plague is typically transmitted to humans and domestic and wild animals via flea bites, but it may also be transmitted by direct contact with infected body fluids or tissues, inhalation of infectious respiratory droplets, or, rarely, by ingestion of contaminated food or water. Contact with infected pets is a common source of plague in pet owners and veterinarians. Cats are particularly susceptible to plague and are often infected by eating infected rodents.

During the European plague epidemics of the 14th century, the predominant flea vector was the oriental rat flea, Xenopsylla cheopis. In the United States, the predominant flea vector of plague is the ground squirrel flea, Oropsylla montana. ${ }^{27}$ Yersinia pestis is amplified in several susceptible rodent reservoir hosts in endemic areas (Table 4). ${ }^{27,28}$

In a 2015 descriptive epidemiologic study of all cases of plague occurring in the United States during 1900 to 2012, investigators described 1006 cases of plague in humans over the 113-y reporting period. Infections were acquired in 18 states, with a male preponderance $(65 \%) .{ }^{29}$ Among cases in which the clinical form was documented ( $\mathrm{n}=913), 82 \%$ were bubonic, $8 \%$ pneumonic, $10 \%$ septicemic, $1 \%$ pharyngeal, and $<1 \%$ gastrointestinal. ${ }^{29}$ When race or ethnicity was known, white non-Hispanic persons comprised 55\% of cases, Asian and Native Americans 16\%, and Hispanics 12\%, with the remainder of unknown race or ethnicity. ${ }^{29}$ Route of exposure was available in only $30 \%$ of cases $(n=305)$, with 106 persons experiencing a known flea bite, 91 handling a sick animal, 64 butchering or skinning a sick animal, and 21 experiencing an animal bite or scratch. ${ }^{29}$ Among case-patients with known flea bites, $90 \%$ of cases were bubonic and $9 \%$ were primary septicemic. ${ }^{29}$ Among the bubonic cases, 66\% exhibited inguinal or femoral lymphadenopathy. ${ }^{29}$ Among persons experiencing an animal bite, scratch, or cough, $76 \%$ were exposed to domestic cats. ${ }^{29}$

From 2001 to 2012, investigators described the annual number of plague cases in the United States as ranging from 1 to 17 with a median of 3 cases. ${ }^{30}$ However, between April 1, 2015, and August 28, 2015, the CDC's Epidemic Intelligence Service reported 11 cases of plague in residents of 6 states: Arizona (2), California (1), Colorado (4), Georgia (1), New Mexico (2), and Oregon (1). ${ }^{31}$ The 2 cases in Georgia and California were linked to exposures near Yosemite National Park. ${ }^{27,31}$ Among the 11 case-patients, the median age was 52 y (range 14-79 y), 9 were male, and 3 patients died (ages 16, 52, and 79 y). ${ }^{31}$ Investigators did not determine why the number of plague cases in 2015 was higher than usual, but climatic trends and their impact on rodent populations were suspected. ${ }^{32}$

After flea bite, the incubation period for symptoms of bubonic plague, including fever, chills, headaches, nausea, and regional lymphadenopathy, ranges from a few days to a week. ${ }^{29}$ With overwhelming infections, hematogenous dissemination may result in secondary pneumonic or septicemic plague. Pneumonic plague may be transmitted from person to person with a short incubation time of $1 \mathrm{~h}$ to 2 to $4 \mathrm{~d}$. The bacteremia of septicemic plague can cause disseminated intravascular coagulation with bleeding and ischemic necrosis of digits and limbs.

The diagnosis of plague can be established microscopically, microbiologically, serologically, and molecularly. Yersinia pestis can be identified microscopically or in culture. Rapid serologic tests can detect the capsule antigen, and polymerase chain reaction assays can detect both the capsular antigen and the plasminogen activator gene.

With early diagnosis, plague is highly responsive to antibiotic therapy, especially with aminoglycosides, fluoroquinolones, and doxycycline. ${ }^{31}$ The mortality rate for untreated plague in the preantibiotic era ranged from 66 to $93 \%$. With early antibiotic therapy, the mortality rate has been reduced to $16 \%$, with the highest case fatality rates found for septicemic plague. ${ }^{29}$ Although an older plague vaccine was recommended for laboratory and field personnel working with Yersinia pestis 
and for troops on maneuvers in endemic areas of Africa and Asia, the vaccine is no longer available in the United States. ${ }^{33}$ Newer vaccines are under development. ${ }^{33}$

\section{PREVENTION AND CONTROL OF RODENT-BORNE INFECTIOUS DISEASES}

Eradicating all rodent reservoir hosts is both impractical because of the widespread distribution of rodents and undesirable because of the importance of rodents as insectivores and prey for larger predators in the ecosystem. The best and most effective strategies for the control and prevention of rodent-borne infectious diseases include (1) reducing rodent habitat around homes, cabins, and recreational areas by removing brush, rock piles, and firewood stacks; (2) storing all unrefrigerated foods, including pet foods, in thick plastic, glass, or metal containers with tight-fitting lids; (3) limiting contact with all wild and peridomestic rodents; (4) avoiding contact with rodent excreta, if possible, and safely disposing of rodent excreta; (5) wearing gloves when handling, butchering, or skinning a potentially infected animal; (6) modifying the built environment to deter rodents from frequenting and colonizing cabins, campsites, households, and workplaces; (7) using insect repellants topically and on clothing when outdoors; and (8) protecting pets with flea and tick control products and not allowing them to roam freely outdoors or share sleeping space with humans in rodent-borne disease-endemic regions. ${ }^{34}$

Only spring-loaded traps that kill rodents immediately should be deployed; live and sticky traps do not kill rodents, thereby allowing them to bite humans during disposal, transmitting Hantaviruses and creating open wounds for potential LS transmission. ${ }^{35}$ While struggling to get free of nonlethal traps, rodents chronically infected with leptospires or Hantaviruses may urinate and emit infectious salivary aerosols, contaminating enclosed spaces. ${ }^{35}$ All areas inhabited by rodents should be cleaned with mops wetted with dilute bleach solutions rather than swept or vacuumed because the latter could create infectious aerosols. ${ }^{35}$

\section{Conclusions}

Wilderness medicine providers should maintain high levels of suspicion for regional rodent-borne diseases in patients who develop febrile illnesses after exposure to contaminated freshwater after heavy rains or floods and after swimming, rafting, or paddling in endemic areas. Public health educational strategies should encourage limiting human contact with rodents; avoiding contact with or safely disposing of rodent excreta; avoiding contact with contaminated floodwaters, especially contact with open wounds; securely containing outdoor food stores; and modifying wilderness cabins and campsites to deter rodent colonization.

Financial/Material Support: All financial/material support for JHD was provided by departmental and institutional sources.

Disclosures: None.

\section{References}

1. Gubler DJ, Reiter P, Ebi KL, Yap W, Nasci R, Patz JA. Climate variability and change in the United States: potential impacts on vector-borne and rodent-borne diseases. Environ Health Perspect. 2001;109(Suppl 2):223-33.

2. Cann KF, Thomas DR, Salmon RL, Wyn-Jones AP, Kay D. Extreme water-related weather events and waterborne disease. Epidemiol Infect. 2013;141(4):671-86.

3. Engelthaler DM, Mosley DG, Cheek JE, Levy CE, Komatsu KK, Ettestad P, et al. Climatic and environmental patterns associated with Hantavirus pulmonary syndrome, Four Corners region, United States. Emerg Infect Dis. 1999;5(1):87-94.

4. Klempa B. Hantaviruses and climate change. Clin Microbiol Infect. 2009;15(6):518-23.

5. Gaynor K, Katz AR, Park SY, Nakata M, Clark TA, Effler PV. Leptospirosis on Oahu: an outbreak associated with flooding of a university campus. Am J Trop Med Hyg. 2007;76(5):882-5.

6. Socolovschi C, Angelakis E, Renvoise A, Fournier PE, Marie JL, Davoust B, et al. Strikes, flooding, rats, and leptospirosis in Marseille, France. Int $J$ Infect Dis. 2011;15(10):e710-5.

7. Mendoza MT, Roxas EA, Ginete JK, Alejandria MM, Roman AD, Leyritana KT, et al. Clinical profile of patients with leptospirosis after a typhoon: a multicentre study. Southeast Asian J Trop Med Pub Health. 2013;44(6):1021-35.

8. Frawley AA, Schafer IJ, Galloway R, Artus A, Ratard RC. Postflooding leptospirosis-Louisiana, 2016. Morb Mort Wkly Rep. 2017;66(42):1158-9.

9. Parmenter RR, Yadav EP, Parmenter CA, Ettestad P, Gage KL. Incidence of plague associated with winter-spring precipitation in New Mexico. Am J Trop Med Hyg. 1999;61(5):814-21.

10. Murphy CM. Writing an effective review article. J Med Toxicol. 2012;8(2):89-90.

11. Ksiazek TG, Peters CJ, Rollin PE, Zaki S, Nichol S, Spiropoulou C, et al. Identification of a new North American Hantavirus that causes acute pulmonary insufficiency. Am J Trop Med Hyg. 1995;52(2):117-23.

12. Van Hook CJ. Hantavirus pulmonary syndrome-The 25th anniversary of the Four Corners outbreak. Emerg Infect Dis. 2018;24(11):2056-60.

13. Yates TL, Mills JN, Parmenter CA, Ksiazek TG, Parmenter RR, Vande Castle JR, et al. The ecology and evolutionary history of an emergent disease: 
hantavirus pulmonary syndrome. Bioscience. 2002;52(11):989-98.

14. Hantavirus pulmonary syndrome in visitors to a National Park-Yosemite Valley, California, 2012. MMWR Morb Mortal Wkly Rep. 2012;61(46):952.

15. Nuñez JJ, Fritz CL, Knust B, Buttke D, Enge B, Novak MG, et al. Hantavirus infections among overnight visitors to Yosemite National Park, California, USA, 2012. Emerg Infect Dis. 2014;20(3):386-93.

16. Jonsson CB, Figueiredo LT, Vapalahti O. A global perspective on Hantavirus ecology, epidemiology, and disease. Clin Microbiol Rev. 2010;23(2):412-41.

17. Warner BM, Dowhanik S, Audet J, Grolla A, Dick D, Strong JE, et al. Hantavisus cardiopulmonary syndrome in Canada. Emerg Infect Dis. 2020;26(12):3020-4.

18. MacNeil A, Ksiazek TG, Rollin PE. Hantavirus pulmonary syndrome, United States, 1993-2009. Emerg Infect Dis. 2011;17(7):1195-201.

19. Knust B, Rollin PE. Twenty-year surveillance for human Hantavirus infections, United States. Emerg Infect Dis. 2013;19(12):1934-7.

20. de St, Maurice A, Ervin E, Schmacher M, Yaglom H, VinHatton E, Melman S, et al. Exposure characteristics of Hantavirus pulmonary syndrome patients, United States, 1993-2015. Emerg Infect Dis. 2017;23(5):733-9.

21. Katz AR, Buchholz AE, Hinson K, Park SY, Effler PV. Leptospirosis in Hawaii, USA, 1999-2008. Emerg Infect Dis. 2011;17(2):221-6.

22. Levett PN. Leptospirosis. Clin Microbiol Rev. 2001;14(2):296-326.

23. Haake DA, Levett PN. Leptospirosis in humans. Curr Top Microbiol Immunol. 2015;387:65-97.

24. Outbreak of acute febrile illness among athletes participating in triathlons-Wisconsin and Illinois, 1998. MMWR Morb Mortal Wkly Rep. 1998;47(28):585-8.

25. Traxler RM, Callinan LS, Holman RC, Steiner C, Guerra MA. Leptospirosis-associated hospitalizations, United States, 1998-2009. Emerg Infect Dis. 2014;20(8):1273-9.
26. Outbreak of leptospirosis among white-water rafters-Costa Rica. 1996. MMWR Morb Mortal Wkly Rep. 1997;46(25):577-9.

27. Danforth M, Novak M, Petersen J, Mead P, Kingry L, Weinburke $M$, et al. Investigation of and response to 2 plague cases, Yosemite National Park, California, USA, 2015. Emerg Infect Dis. 2016;22(12):2045-53.

28. Brown HE, Ettestad P, Reynolds PJ, Brown TL, Hatton ES, Holmes JL, et al. Climatic predictors of the intra- and interannual distribution of plague cases in New Mexico based on 29 years of animal-based surveillance data. Am J Trop Med Hyg. 2020;82(1):95-102.

29. Kugeler KJ, Staples JE, Hinckley AF, Gage KL, Mead PS. Epidemiology of human plague in the United States, 1900-2012. Emerg Infect Dis. 2015;21(1):16-22.

30. Adams DA, Jajosky RA, Ajani U, Kriseman J, Sharp P, Onwen DH, et al. Summary of notifiable diseases-United States, 2012. MMWR Morb Mortal Wkly Rep. 2014;61(53):1-121.

31. Kwit N, Nelson C, Kugeler K, Petersen J, Plante L, Yaglom H, et al. Human plague-United States, 2015. MMWR Morb Mortal Wkly Rep. 2015;64(33):918-9.

32. Ben Ari T, Gershunov A, Gage KL, Snall T, Ettestad P, Kausrud KL, et al. Human plague in the USA: the importance of regional and local climate. Biol Lett. 2008;4(6):737-40.

33. Sun W, Singh AK. Plague vaccine: recent progress and prospects. NPJ Vaccines. 2019;4:11.

34. Danforth ME, Messenger S, Buttke D, Weinburke M, Carroll G, Hacker G, et al. Long-term rodent surveillance after outbreak of Hantavirus infection, Yosemite National Park, California, USA, 2012. Emerg Infect Dis. 2020;26(3):560-7.

35. Mills JN, Corneli A, Young JC, Garrison LE, Khan AS, Ksiazek TG. Hantavirus pulmonary syndrome-United States: Updated recommendations for risk reduction. MMWR Recomm Rep. 2002;51(RR-9):1-12. 